\title{
Văn hóa doanh nghiệp, bắt nguồn từ những giá trị
}

Airtech Thế Long

May 15, 2019

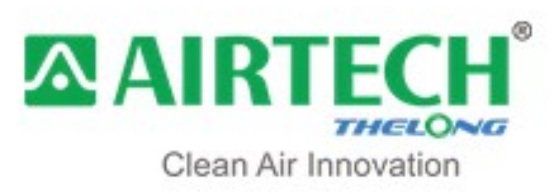

https://airtechthelong.com.vn/ja/lop-hoc-van-hoa-doanh-nghiep.html 


\section{Lớp học văn hóa doanh nghiệp}

\section{Văn hóa doanh nghiệp, bắt nguồn từ nhũng giá trị}

Có́t lõi của văn hóa doanh nghiệp là tinh thần doanh nghiệp và quan điểm giá trị của doanh nghiệp. Trong cuốn sách Văn minh làm giàu và nguồn gốc của cải của TS.Vương Quân Hoàng, chúng ta đã được đề cập tới khái niệm giá trị. Giải thích một cách đơn giản, giá trị là một cái gì đó mà người ta cảm thấy quan trọng, có ích. Cụm từ “Quan trọng” và "Có ích lợi” là rất đáng lưu tâm trong xây dựng văn hóa doanh nghiệp. Bởi lẽ lãnh đạo công ty sẽ rất khó xây dựng văn hóa doanh nghiệp, nếu không truyền đạt được những ích lợi mà văn hóa doanh nghiệp đem lại. Nhân viên cần được giáo dục nhận thức rằng việc đeo thẻ nhân viên, mặc đồng phục là thể hiện sự tự hào là thành viên của công ty, và có ích cho công việc của họ chứ không phải họ mang những thứ đó để làm quảng cáo.

Rất nhiều lãnh đạo đã mắc lỗi khi áp đặt văn hóa mà không khơi gợi nhận thức của nhân viên mình với các giá trị văn hóa. Nếu không giảng giải được cặn kẽ hệ thống các giá trị văn hóa của doanh nghiệp có ích lợi gì với nội bộ tổ chức, tất yếu mọi hình thức triển khai chỉ là phong trào. Một câu hỏi được đặt ra rằng, vậy những giá trị nào là hợp lý và giá trị nào là không hợp lý. Điều này tùy thuộc rất nhiều vào từng tổ chức riêng biệt, nhưng tựu chung lại, có một số giá trị được đề cao trong nội bộ tổ chức ở Việt Nam đó là:

- Sự thành thực (thể hiện là nói thật, không gian dối, cam kết thực hiện những gì mình hứa hẹn và đảm bảo đúng những gì mình sẽ thực hiện)

- Sự tự giác (thể hiện ở mức độ sẵn sàng với công việc, không ngại khó khăn, làm việc hết mình vì lợi ích của tổ chức)

- Sự khôn khéo (biết nói những gì cần nói, hỏi những điều cần hỏi, tranh luận những điều đáng tranh luận và sắp xếp những gì hợp lý nhất)

Ngoài ra còn một số giá trị khác được đề cập tới như sự tự tin, sáng tạo ... Những giá trị này sẽ là nền tảng định hướng cho văn hóa của doanh nghiệp.

Thực tế, văn hóa tồn tại khách quan và doanh nghiệp nào cũng có văn hóa của riêng mình. Chỉ có điều văn hóa được thể hiện như thế nào và doanh nghiệp đó có phát hiện ra những giá trị tốt để phát huy và những giá trị chưa tốt để thay đổi hay không. Văn hóa doanh nghiệp bắt nguồn từ những gì nhỏ nhất, cụ thể, không chung chung.

Nhận thức được tầm quan trọng của Văn hóa Doanh nghiệp đối với sự phát triển bền vững của công ty, Chủ nhật ngày 23/07/2017, Ban lãnh đạo Công ty Cổ phần Airtech Thế Long đã tổ chức Lớp học "Văn hóa Doanh nghiệp " tại Văn phòng Công ty cho toàn thế CB-CNVdo giảng viên Tiến Sỹ Ngô Trung Hòa trực tiếp giảng dạy.

Buổi học đã đã diễn ra trong không khí vui vee, sôi nổi và tràn đầy bổ ích. Thông qua lớp học, các CB-CNV được tìm hiểu về khái niệm Văn hóa Doanh Nghiệp, tầm quan trọng của Văn hóa Doanh Nghiệp đối với sự phát triển lâu dài của Công ty cũng như cách thức xây dựng Văn hóa Doanh Nghiệp. 


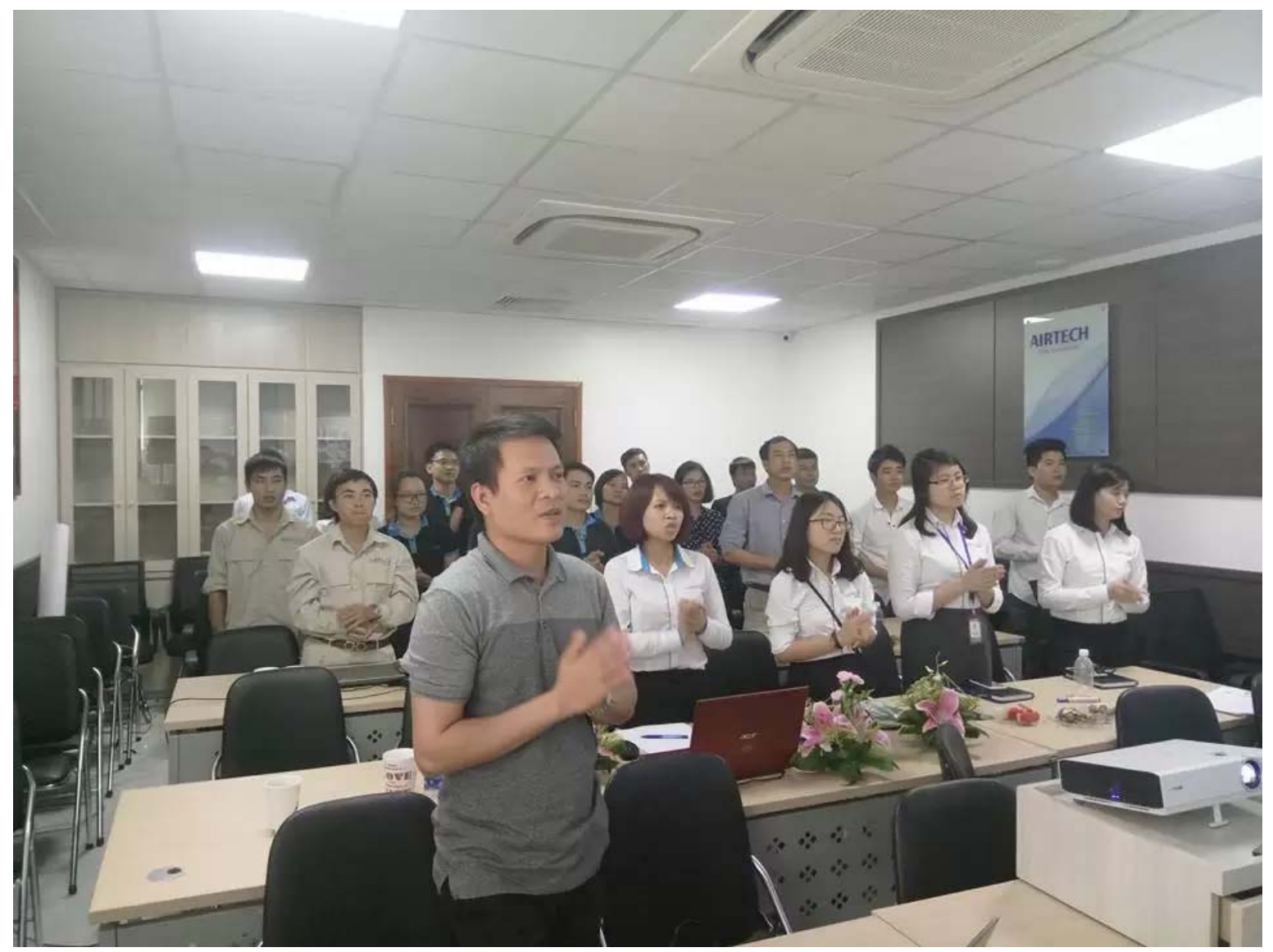

Toàn thể CB-CNV hát vang Bài ca Thế Long mở đầu tiết học

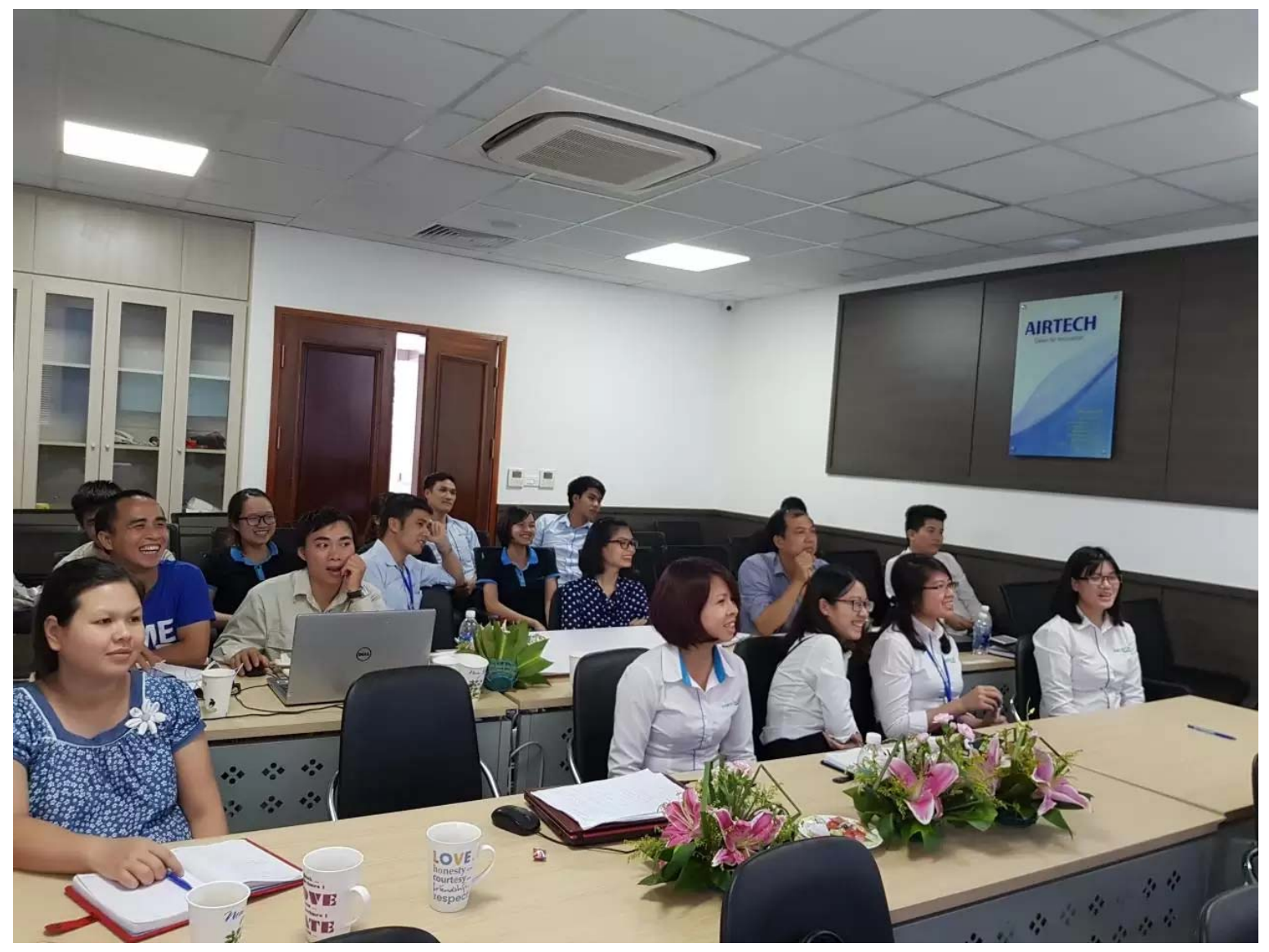

CB-CNV Công ty Thế Long hào hứng trong lóp học 


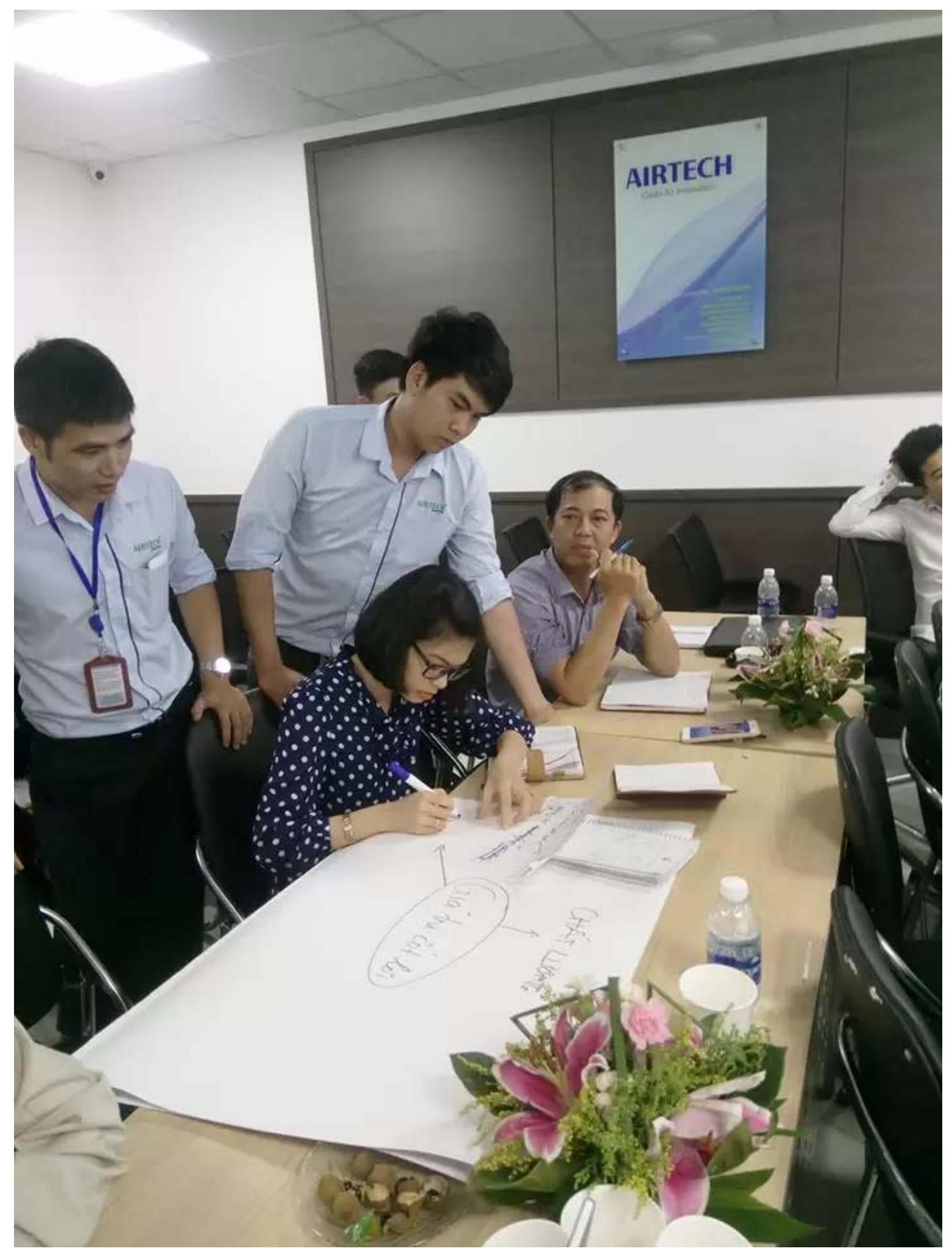

Các đội cùng nhau thảo luận xây dựng nội dung giá trị cốt lõi của Doanh nghiệp 


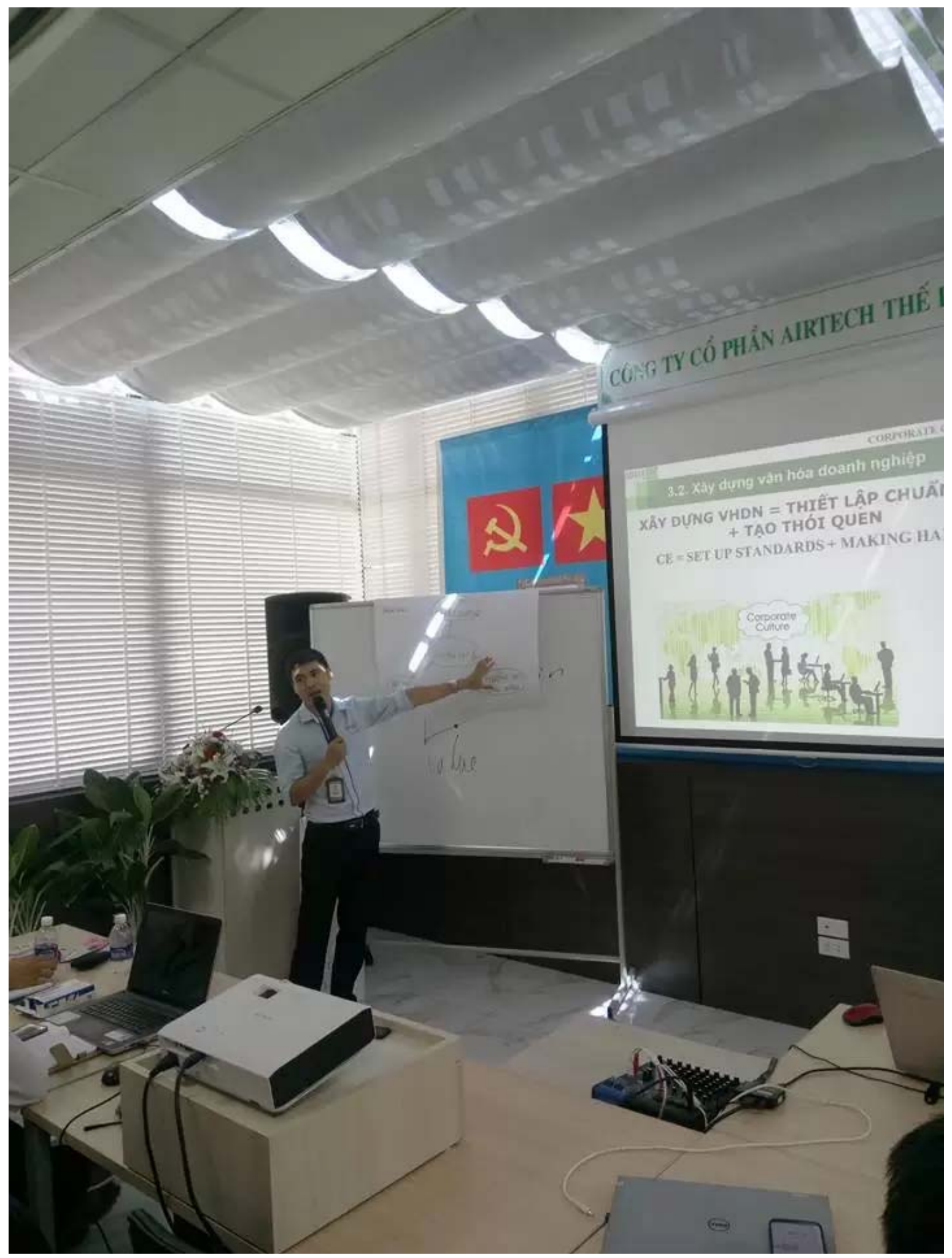

Anh Nguyễn Tài Sơn - GĐ Dự án trình bày về vấn đề giá trị cốt lõi của Doanh nghiệp

Cảm ơn Ban lãnh đạo Công ty cùng Tiến sỹ Ngô Trung Hòa đã mang lại một tiết học bổ ích cho toàn bộ CB-CNV Công ty Cổ phần Airtech Thế Long. Sau tiết học này, các anh chị đã có thêm những kiến thức và giá trị mới cho bản thân mình. Hẹn gặp lại mọi người ở các tiết học tiếp theo của Công ty Thế Long./. 


\section{Tài liệu tham khảo:}

[1] Airtech Thế Long. (2019). Văn hóa doanh nghiệp, bắt nguồn từ những giá trị. Lớp học văn hóa doanh nghiệp. https://airtechthelong.com.vn/ja/lop-hoc-van-hoa-doanhnghiep.html

[2] Vương Quân Hoàng. (2007). Văn minh làm giàu \& Nguồn gốc của cải. Nxb Chính trị quốc gia, Hà Nội. 